\title{
Contribuições da assistência de enfermagem à gestante com ansiedade: prevalência $\mathrm{e}$ fatores associados
}

\author{
Contributions of nursing care to pregnant women with anxiety: prevalence and associated factors \\ Contribuciones de los cuidados de enfermería a gestantes con ansiedad: prevalencia y factores \\ associados
}

Recebido: 20/04/2021 | Revisado: 27/04/2021 | Aceito: 30/04/2021 | Publicado: 07/05/2021

Airton César Leite

ORCID: https://orcid.org/0000-0001-7184-8488

Centro Universitário Santo Agostinho, Brasil E-mail: ainton.cesar2014@gmail.com

Mariana Pereira Barbosa Silva

ORCID: https://orcid.org/0000-0003-0852-8099 Universidade Estadual do Piauí, Brasil E-mail: marianapbsilvaa@gmail.com

Rayssa Stéfani Sousa Alves

ORCID: https://orcid.org/0000-0002-9666-675X Pontifícia Universidade Católica de Goiás, Brasil

E-mail: rayssastefani02@gmail.com

Marciele de Lima Silva

ORCID: https://orcid.org/0000-0003-2827-5316 Instituto de Educação Superior da Paraíba, Brasil

E-mail: marcieledelsilva@gmail.com

Juliana Torres Avelino

ORCID: https://orcid.org/0000-0002-8732-1856

Centro Universitário Santo Agostinho, Brasil

E-mail: Juliana_avelinno@hotmail.com

Thatielly Rodrigues de Morais Fé

ORCID: https://orcid.org/0000-0001-9400-1116

Faculdade Estácio de Teresina, Brasil

E-mail: thatiellymorais@outlook.com

Laide dos Santos Brasil Silva

ORCID: https://orcid.org/0000-0001-5593-7173

Centro Universitário Santo Agostinho, Brasil

E-mail: laidebr.98@gmail.com

Laryce Steffane de Carvalho Borges

ORCID: https://orcid.org/0000-0002-5303-2773

Centro Universitário Santo Agostinho, Brasil E-mail: Laryce.borges50@gmail.com

João Vitor Martins Amorim

ORCID: https://orcid.org/0000-0002-5126-8109

Centro Universitário Santo Agostinho, Brasil E-mail: mjoaovitor783@gmail.com Jarles Ribeiro Lima

ORCID: https://orcid.org/0000-0002-7624-9254 Centro Universitário Santo Agostinho, Brasil E-mail: Jarlleslima88@gmail.com

Raimunda da Silva Sousa Neta

ORCID: https://orcid.org/0000-0001-5927-0046 Centro Universitário Santo Agostinho, Brasil E-mail: raynettasousa@gmail.com

Sarah Vitória Floriano de Sousa ORCID: https://orcid.org/0000-0002-6973-8885 Universidade Estadual do Piauí, Brasil E-mail: s.vitoria98@hotmail.com

Erica Williams de Moreira Lima ORCID: https://orcid.org/0000-0003-3957-5699

Centro Universitário Uninovafapi, Brasil

E-mail: williams-erica1992@outlook.com

Shandallyane Ludce Pinheiro de Farias ORCID: https://orcid.org/0000-0002-9180-6733

Centro Universitário Santo Agostinho, Brasil E-mail: ludcepinheiro@hotmail.com 


\author{
Nádia Domingas Santos \\ ORCID: https://orcid.org/0000-0003-2325-6634 \\ Centro Universitário Santo Agostinho, Brasil \\ E-mail: nadiaumb@gmail.com \\ Sijomara Maria Costa Freitas \\ ORCID: https://orcid.org/0000-0003-3443-7334 \\ Centro Universitário Uninassau Redenção, Brail \\ E-mail: sijomara.costa@icloud.com \\ Aryanna Quadros Maniçoba \\ ORCID: https://orcid.org/0000-0003-0575-3485 \\ Centro Universitário Uninovafapi, Brasil \\ E-mail: aryannaquadros.61@gmail.com \\ Lara Gabrielle Lopes Fonseca \\ ORCID: https://orcid.org/0000-0003-3116-1707 \\ Centro Universitário Unifacid, Brasil \\ E-mail: larajs2212@gmail.com \\ Nathally Costa Oliveira \\ ORCID: https://orcid.org/0000-0001-8748-0817 \\ Centro Universitário Unifacid, Brasil \\ E-mail: nathallycosta54@ gmail.com \\ Ana Emília Araújo de Oliveira \\ ORCID: https://orcid.org/0000-0002-7813-4442 \\ Universidade Estadual da Paraíba, Brasil \\ E-mail: anaemiliaoliveira@hotmail.com \\ Joelma Maria dos Santos da Silva Apolinário \\ ORCID: https://orcid.org/0000-0001-9521-9432 \\ Faculdade Maurício de Nassau, Brasil \\ E-mail: jo.silva00@hotmail.com \\ Simone Barroso de Carvalho \\ ORCID: https://orcid.org/0000-0001-7428-8420 \\ Universidade Federal do Piauí, Brasil \\ E-mail: simonebcarvalho2009@hotmail.com \\ Elvira Marques da Luz Dias \\ ORCID: https://orcid.org/0000-0001-7966-0877 \\ Universidade Brasil, Brasil \\ E-mail: elviraluzz@hotmail.com \\ José Ronildo da Costa \\ ORCID: https://orcid.org/0000-0002-2730-6320 \\ Universidade Regional do Cariri, Brasil \\ E-mail: ronildo156@hotmail.com
}

\title{
Resumo
}

Analisar as evidências científicas publicadas acerca das contribuições da assistência de enfermagem à gestante com ansiedade: prevalência e fatores associados. O presente estudo trata de uma revisão bibliográfica do método revisão integrativa da literatura, realizado nos meses entre janeiro a abril de 2021. A busca efetuou-se, através da Plataforma BVS, utilizando as bases de dados LILACS, BDENF, Google Acadêmico e por meio da Biblioteca Eletrônica da Saúde - SCIELO. Aderindo-se através dos descritores/palavras chaves: "Cuidados de enfermagem", "Ansiedade", "Gestação", combinados com o operador booleano "AND”. A gestação envolve mudanças nos aspectos hormonais, físicos, psicológicos, familiares e sociais, na possibilidade de adequações e reestruturações na vida das mulheres. Essas mudanças têm desencadeado, muitas vezes, um processo de vulnerabilidade às mulheres grávidas podendo agravar à saúde mental e desenvolver transtornos mentais. A prevalência da ansiedade, aflige cerca de $20 \%$ das mulheres. Dessa forma, os riscos obstétricos que envolvem o desenvolvimento de uma gestação colocam a mulher em estado susceptível à ansiedade, deixando-a dual: frágil, por medo das alterações gravídicas, e ao mesmo tempo feliz pelo processo de concepção e formação de uma nova vida. Evidenciou-se no estudo, que é necessário que os enfermeiros realizem um acolhimento integral durante o pré-natal, investigando questões clínicas e também psicossociais para que assim possam contribuir, de maneira significativa, na melhora nos níveis de ansiedade e depressão desta gestante, proporcionando um acompanhamento pré-natal de qualidade.

Palavras-chave: Cuidados de enfermagem; Ansiedade; Gestação.

\begin{abstract}
Analyze the published scientific evidence about the contributions of nursing care to pregnant women with anxiety: prevalence and associated factors. The present study deals with a bibliographic review of the integrative literature review method, carried out in the months between January and April 2021. The search was carried out, through the VHL Platform, using the databases LILACS, BDENF, Google Scholar and through the Electronic Health Library SCIELO. Adhering to the descriptors / keywords: "Nursing care", "Anxiety", "Gestation", combined with the Boolean operator "AND". Pregnancy involves changes in hormonal, physical, psychological, family and social
\end{abstract}


aspects, in the possibility of adjustments and restructuring in women's lives. These changes have often triggered a process of vulnerability to pregnant women, which can worsen mental health and develop mental disorders. The prevalence of anxiety afflicts about $20 \%$ of women. Thus, the obstetric risks that involve the development of a pregnancy put the woman in a state susceptible to anxiety, leaving her dual: fragile, for fear of pregnancy changes, and at the same time happy for the process of conceiving and forming a new life. It was evidenced in the study, that it is necessary that nurses perform a full reception during the prenatal period, investigating clinical and also psychosocial issues so that they can contribute, in a significant way, in the improvement of the levels of anxiety and depression of this pregnant woman, providing quality prenatal care.

Keywords: Nursing care; Anxiety; Gestation.

\section{Resumen}

Analizar la evidencia científica publicada sobre los aportes de los cuidados de enfermería a la gestante con ansiedad: prevalencia y factores asociados. El presente estudio trata de una revisión bibliográfica del método de revisión integradora de la literatura, realizada entre enero y abril de 2021. La búsqueda se realizó, a través de la Plataforma BVS, utilizando las bases de datos LILACS, BDENF, Google Scholar y a través de la Biblioteca Electrónica de Salud. - SCIELO. Siguiendo los descriptores / palabras clave: "Cuidados de enfermería", "Ansiedad", "Gestación", combinados con el operador booleano "Y". El embarazo implica cambios en los aspectos hormonales, físicos, psicológicos, familiares y sociales, en la posibilidad de ajustes y reestructuraciones en la vida de las mujeres. Estos cambios a menudo han desencadenado un proceso de vulnerabilidad en las mujeres embarazadas, que puede empeorar la salud mental y desarrollar trastornos mentales. La prevalencia de la ansiedad afecta aproximadamente al $20 \%$ de las mujeres. Así, los riesgos obstétricos que implica el desarrollo de un embarazo ponen a la mujer en un estado susceptible a la ansiedad, dejándola dual: frágil, por miedo a los cambios del embarazo, y al mismo tiempo feliz por el proceso de concebir y formar una nueva vida. Se evidenció en el estudio, que es necesario que las enfermeras realicen una recepción integral durante el período prenatal, investigando aspectos clínicos y también psicosociales para que puedan contribuir, de manera significativa, en la mejora de los niveles de ansiedad y depresión de esta mujer embarazada, brindándole atención prenatal de calidad.

Palabras clave: Cuidado de enfermera; Ansiedad; Gestación.

\section{Introdução}

A gestação é vista como um momento de transição, extremamente significativo durante a vida da mulher e que exige inúmeras adaptações. Acredita-se que durante a gravidez a mulher está mais vulnerável ao desenvolvimento de transtornos de ansiedade. Esses transtornos podem acarretar prejuízos para a gestante, o feto e, às vezes, até para o cônjuge. Sendo assim, o entendimento dos fatores associados à ansiedade durante a gestação é de grande importância, já que é uma oportunidade para a equipe multidisciplinar prevenir, detectar e tratar tais transtornos (Araújo, Pacheco, Pimenta, \& Kac, 2008).

A gravidez é um período em que alterações fisiológicas, psíquicas, hormonais e sociais se fazem presentes e aumentam o risco de sofrimento emocional e de morbidade psiquiátrica nesta fase da vida da mulher. Algumas mulheres podem vivenciar a gravidez como uma fonte de felicidade, satisfação e autorrealização, outras, porém, podem vivenciar, neste momento, alterações em sua saúde mental, como o desenvolvimento de ansiedade (Silva, Nogueira, Clápis, \& Leite, 2019).

Segundo Martins et al. (2020), a maternidade é uma experiência pessoal vivenciada por mulheres de modo singular, portanto, a atenção pré-natal deve incluir não somente práticas de promoção e prevenção da saúde, como também de diagnóstico e tratamento adequado de possíveis problemas decorrentes desse período. A gestação é um período de grandes mudanças para as mulheres, representadas por uma variação hormonal e alterações nas características corporais que repercutem em seu cotidiano, as quais, apesar de serem necessárias para o desenvolvimento fetal, podem provocar certos desconfortos.

Sabe-se que, em situações de mudanças, é natural e positivo que as gestantes possam sentir medo e/ou ansiedade, porém, esses sentimentos, quando retidos, originam tensão, que causa a dor e induzem a uma intensificação do medo e da ansiedade, alterando a respiração e o uso da energia, podendo afetar o feto. Além disso, pode ocorrer um esgotamento da mulher, prejudicando a tranquilidade de um parto normal e levando a uma cesariana desnecessária. Dessa forma, torna-se necessária a abordagem terapêutica para controle dos desconfortos e promoção do bem-estar das gestantes (Martins et al., 2019). 
A ansiedade é considerada uma "resposta fisiológica natural", causando os sintomas de taquicardia, sentimento de medo generalizado, medo de desastre eminente, tensão e inquietação. Esses sintomas também podem estar relacionados a doenças, como fobias, síndrome do pânico, transtornos obsessivo-compulsivos, ansiedade generalizada, entre outros. Na gestação, a ansiedade tornou-se um achado comum devido ao ciclo de vida vivenciado pela mulher, caracterizado como momento de fragilidade emocional, flutuação hormonal e mudanças sociais que influenciam diretamente em sua saúde emocional (Silva et al., 2020).

De acordo com Araújo et al. (2020), a ansiedade gerada na gravidez, segundo os distúrbios de maior frequência, pode ser definida como um conjunto de preocupações e medos relacionados com o período gestacional, parto, saúde do feto/recémnascido e as incertezas futuras com a relação mãe e filho. Os sintomas desencadeados pelos distúrbios são inúmeros, dentre eles podemos citar dores de cabeça, palpitações do coração, ataques de pânico, tensões musculares, problemas digestivos e depressão.

Segundo Alves, Pereira, e Serqueira (2018), o ciclo gestacional é um período marcado por inúmeras modificações que necessitam de um processo de adaptação contínuo, no qual se cumprem diversas tarefas de desenvolvimento. A mulher deverá se adaptar tanto às mudanças ocorridas no seu corpo quanto à mudança de papeis gerada pela maternidade, tal como: de sua condição de filha para a de mãe, além do reajuste do seu relacionamento conjugal, sua situação socioeconômica e profissional, que são mais impactantes em primíparas, porém multíparas podem vivê-las com intensidade. Esse período de transição é marcado por um aumento na vulnerabilidade emocional e social, ocorrendo incertezas e expectativas diante do nascimento, em que se idealiza um filho perfeito, saudável e sem necessidade de internação.

Assim, tendo em vista um processo que impõe tantas exigências à mulher, é notória a presença da ansiedade, mesmo que excluindo a sua dimensão patológica, os estudos são consensuais quanto à existência de uma morbidade aumentada do tipo ansiosa ou depressiva durante a gravidez. Altos níveis de ansiedade possuem comprovadas implicações na saúde bem-estar da mãe, bem como implicam de forma direta na saúde e desenvolvimento do feto, desde o intra-útero, apontando os riscos de sofrer malformações congênitas, ser prematuro e apresentar baixo peso ao nascer, o que evidencia a interferência direta da ansiedade materna no funcionamento neurocomportamental fetal (Alves, Pereira, \& Serqueira, 2018).

Diante da temática em discussão, surge como questão norteadora do estudo: "Quais as contribuições da assistência de enfermagem à gestante com ansiedade: prevalência e fatores associados"? Assim, o objetivo do presente estudo é analisar as evidências científicas publicadas acerca das contribuições da assistência de enfermagem à gestante com ansiedade: prevalência e fatores associados.

A realização do estudo relacionado à temática, é essencial para a construção coletiva do conhecimento, pois, o estudo possibilita a sociedade acadêmica e cientifica a ampliar o conhecimento sobre as contribuições da assistência de enfermagem à gestante com ansiedade: prevalência e fatores associados. Desse modo, o estudo trará contribuições importantes para a comunidade científica e para a sociedade, na medida em que acrescentará as evidências científicas discussões relevantes a respeito dessa temática tão importante.

\section{Metodologia}

O presente estudo trata de uma revisão bibliográfica do método revisão integrativa da literatura, realizado nos meses entre janeiro a abril de 2021. A revisão configura-se, portanto, como um tipo de revisão da literatura que reúne achados de estudos desenvolvidos mediante diferentes metodologias, permitindo aos revisores sintetizar resultados sem ferir a filiação epistemológica dos estudos empíricos incluídos. Para que esse processo concretize-se de maneira lógica, isenta de desatinos epistemológicos, a revisão requer que os revisores procedam à análise e à síntese dos dados primários de forma sistemática e rigorosa (Soares et al., 2014). 
A revisão da literatura serve para reconhecer a unidade e a diversidade interpretativa existente no eixo temático em que se insere o problema em estudo, para ampliar, ramificar a análise interpretativa, bem como para compor as abstrações e sínteses que qualquer pesquisa requer colaborando para a coerência nas argumentações do pesquisador. Nesse sentido, a revisão integrativa é um método que tem como finalidade reunir e sintetizar resultados de pesquisas sobre um delimitado tema ou questão, de maneira sistemática e ordenada e abrangente, contribuindo para o aprofundamento do conhecimento do tema investigado (Ferenhof \& Fernandes, 2016).

O processo de revisão da literatura requer a elaboração de uma síntese pautada em diferentes tópicos, capazes de criar uma ampla compreensão sobre o conhecimento. A revisão da literatura é um primeiro passo para a construção do conhecimento científico, pois é através desse processo que novas teorias surgem, bem como são reconhecidas lacunas e oportunidades para o surgimento de pesquisas num assunto específico (Botelho, Cunha, \& Macedo, 2011).

A revisão integrativa é uma ferramenta de investigação que permite à procura, a avaliação crítica e a síntese de evidências disponíveis sobre o tema investigado, em que o produto final é o estado do conhecimento, a implementação de intervenções efetivas na prestação de cuidados e na redução de custos. Além disso, permite a identificação de fragilidades, que poderão conduzir ao desenvolvimento de futuras investigações (Sousa, Marques-Vieira, Severino, \& Antunes, 2017).

A revisão integrativa permite que o leitor reconheça os profissionais que mais investigam determinado assunto, separar o achado científico de opiniões e ideias, além de descrever o conhecimento no seu estado atual, promovendo impacto sobre a prática clínica. Este método de pesquisa proporciona aos profissionais de saúde dados relevantes de um determinado assunto, em diferentes lugares e momentos, mantendo-os atualizados e facilitando as mudanças na prática clínica como consequência da pesquisa. Dessa forma, acreditamos que a revisão integrativa é uma ferramenta importante no processo de comunicação dos resultados de pesquisas, facilitando a utilização desses na prática clínica, uma vez que proporciona uma síntese do conhecimento já produzido e fornece subsídios para a melhoria da assistência à saúde (Mendes, Silveira, \& Galvão, 2008).

Figura 1. Fluxograma fases distintas da revisão integrativa.

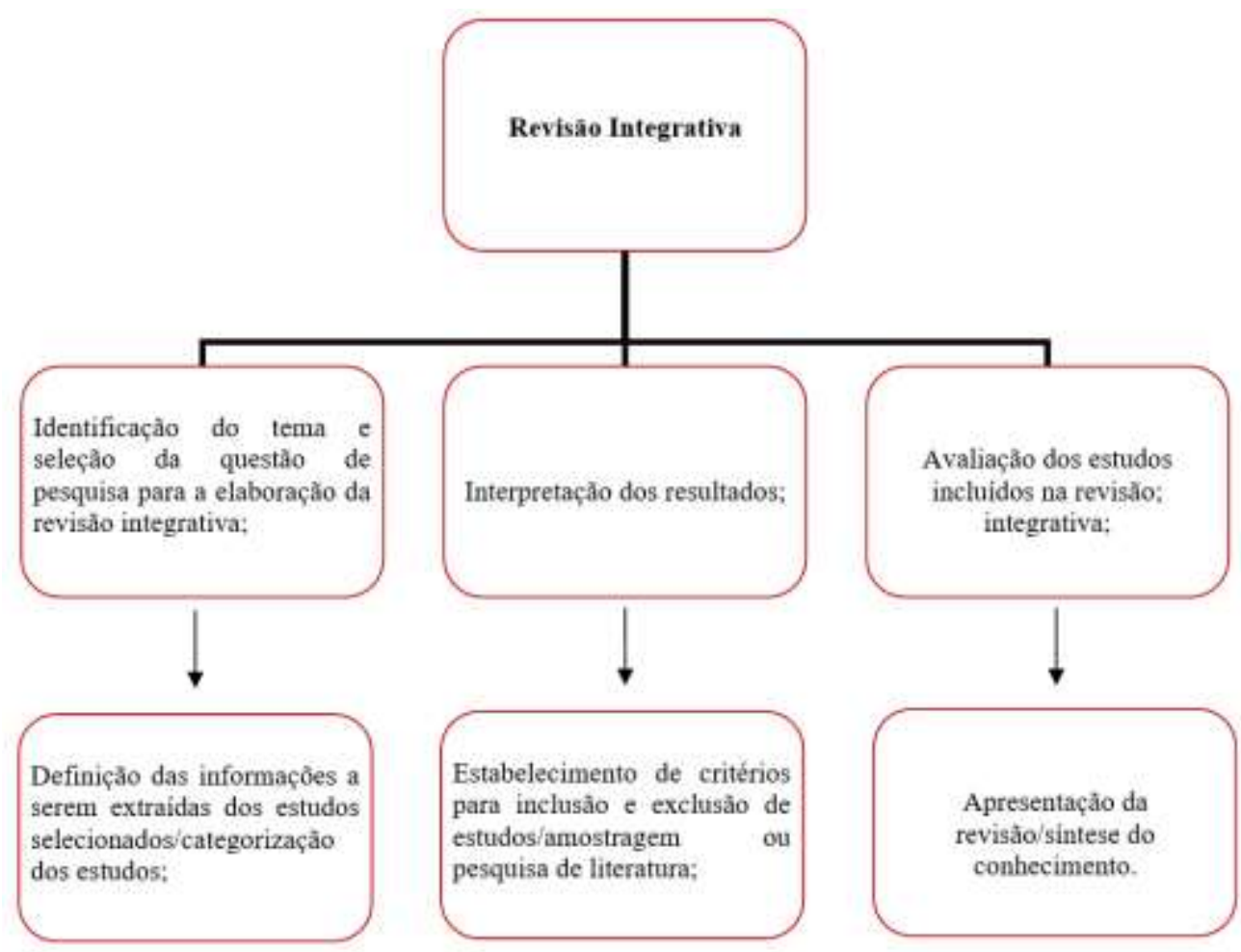

Fonte: Mendes, Silveira e Galvão (2008). 
A revisão integrativa é um tipo de pesquisa que fornece informações mais amplas de maneira sistemática, ordenada e abrangente, sobre um assunto ou tema, com a finalidade de sintetizar resultados obtidos em pesquisa sobre temas ou questões. A definição das informações a serem extraídas dos estudos selecionados por categorização; avaliação dos estudos incluídos; interpretação dos resultados; e apresentação da revisão/síntese do conhecimento (Ercole, Melo, \& Alcoforado, 2015).

Estudo elaborado com abordagem qualitativa tornando-se importante a interpretação por parte do pesquisador com suas opiniões sobre o fenômeno em estudo. Neste tipo de pesquisa destacam-se algumas características como: a pesquisa qualitativa, em geral, ocorre no ambiente natural com coleta direta de dados e o pesquisador é o principal instrumento; os dados coletados são preferencialmente descritivos; a preocupação do processo é predominante em relação à do produto; a análise de dados e informações tende a seguir um processo indutivo (Pereira, Shitsuka, Parreira, \& Shitsuka, 2018).

A pesquisa qualitativa envolve uma abordagem interpretativa do mundo, o que significa que seus pesquisadores estudam as coisas em seus cenários naturais, tentando entender os fenômenos em termos dos significados que as pessoas a eles conferem. A pesquisa qualitativa atribui importância fundamental aos depoimentos dos atores sociais envolvidos, aos discursos e aos significados transmitidos por eles. Nesse sentido, esse tipo de pesquisa preza pela descrição detalhada dos fenômenos e dos elementos que o envolvem (Augusto, Souza, Dellagnelo, \& Cario, 2014).

De acordo com Souza, Silva, e Carvalho (2010), a ser realizada nas seguintes etapas: 1- Elaboração da pergunta norteadora; 2- Busca nas bases de dados e amostragem; 3- Coleta de dados, 4- Análise crítica.

Para responder à questão norteadora do estudo: "Quais as contribuições da assistência de enfermagem à gestante com ansiedade: prevalência e fatores associados"? Aplicou-se os descritores/palavras-chaves: "Cuidados de enfermagem", "Ansiedade", "gestação".

A busca efetuou-se, através da Plataforma da Biblioteca Virtual em Saúde - BVS, utilizando as bases de dados Literatura Latino-Americana e do Caribe em Ciências da Saúde (LILACS), Base de Dados de Enfermagem (BDENF), Google Acadêmico e por meio da Biblioteca Eletrônica da Saúde - Scientific Electronic Library Online (SCIELO). Aderindo-se através dos descritores/palavras chaves: "Cuidados de enfermagem", "Ansiedade", "Gestação", combinados com o operador booleano "AND".

Os critérios de inclusão estabelecidos foram: artigos originais disponibilizados na íntegra, completos, que abrangessem a temática e na forma online, publicados nos idioma português, inglês e espanhol, publicações que respondiam a questão norteadora do estudo. Os critérios de exclusão estabelecidos na seleção foram: artigos incompletos, artigos duplicados, teses, dissertações, monografias e manuais. No início da pesquisa obteve-se 17850 publicações, após a aplicação dos critérios de inclusão e exclusão totalizou-se parcialmente 1783 artigos, depois de uma leitura mais precisa aderiu-se um total final de 13 publicações de acordo para serem trabalhadas no estudo.

O fluxograma representado abaixo, caracteriza a estratégia de coleta de dados utilizada pelos autores, no sentido de detalhar as principais evidencias encontradas no estudo. 
Figura 2. Fluxograma Estratégia de Busca - Bases de Dados, Teresina-PI, Brasil, 2021.

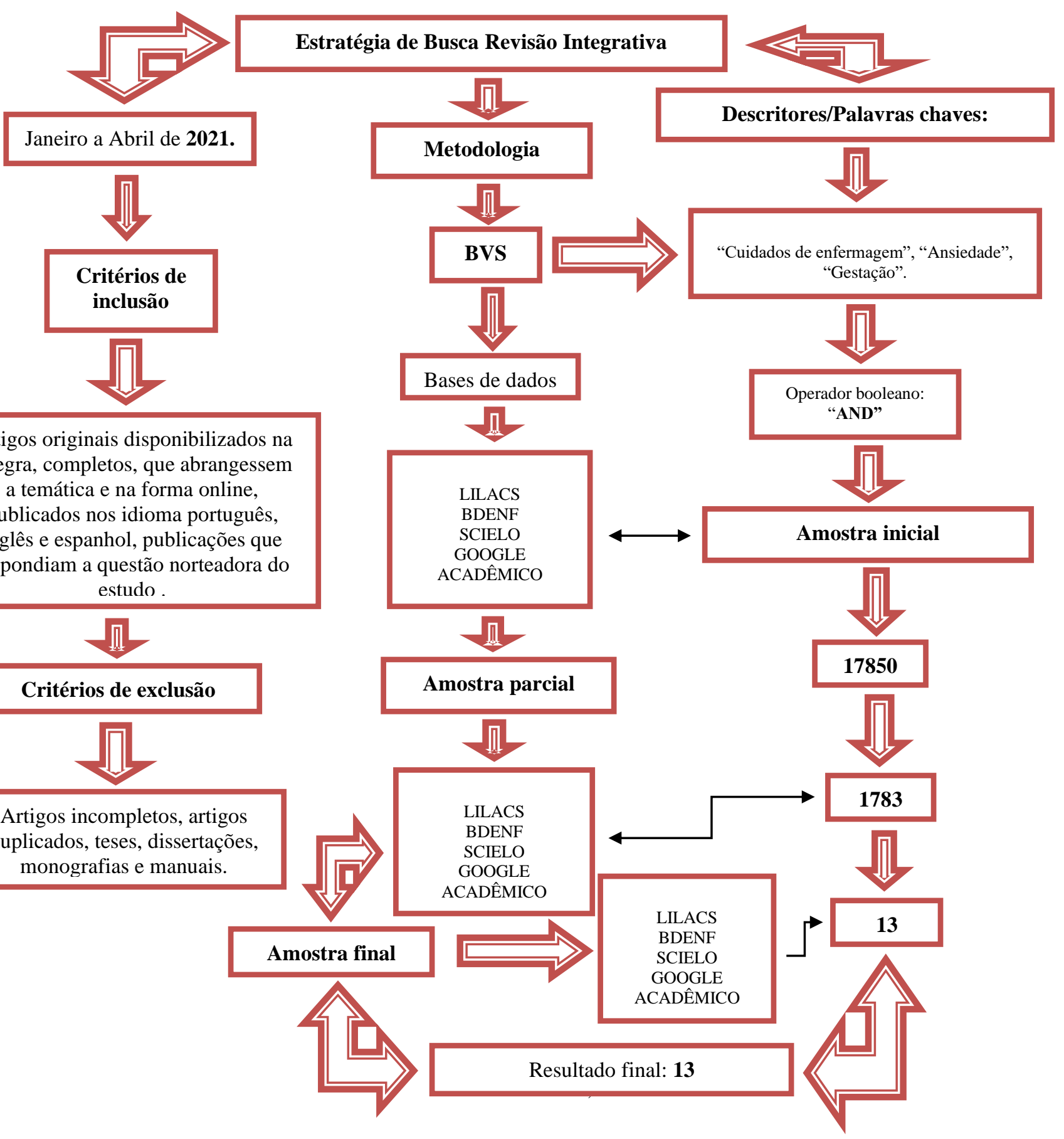

Fonte: Autores (2021).

No Fluxograma 2, estão expostos a estratégia de busca, bases de dados, período de realização do estudo, critérios de inclusão e exclusão, amostra inicial, parcial e final, de acordo com a quantidade de artigos que irão compor os resultados do estudo.

O presente estudo assegura os aspectos éticos, garantindo a autoria dos artigos pesquisados, utilizando para as citações e referências dos autores as normas APA. Os preceitos éticos estabelecidos no que se refere a zelar pela legitimidade das informações, privacidade e sigilo das informações, quando necessárias, tornando os resultados desta pesquisa públicos. Os pesquisadores buscaram a legitimidade e fidelidade nas citações dos autores seja nas citações diretas ou parafraseadas no estudo. 


\section{Resultados e Discussão}

Diante dos resultados obtidos no estudo por meio da estratégia de busca, os autores delinearam variáveis para melhor descrever as evidências encontradas na pesquisa. O quadro a seguir caracteriza os artigos com base nas variáveis propostas: número do artigo, periódico, autor e ano de publicação, tipo de estudo, título, objetivo, resultados em evidências e conclusões importantes.

Quadro 1. Caracterização dos artigos selecionados para o estudo.

\begin{tabular}{|c|c|c|c|c|c|c|}
\hline $\mathbf{N}$ & Periódico & $\begin{array}{l}\text { Autor e } \\
\text { Ano }\end{array}$ & $\begin{array}{l}\text { Tipo de } \\
\text { Estudo }\end{array}$ & Título & Objetivo & $\begin{array}{c}\text { Resultados em evidências e conclusões } \\
\text { importantes }\end{array}$ \\
\hline 1 & $\begin{array}{l}\text { Research, Society } \\
\text { and Development. }\end{array}$ & $\begin{array}{l}\text { Araújo et } \\
\text { al., } 2020 .\end{array}$ & $\begin{array}{l}\text { Estudo } \\
\text { qualitativo. }\end{array}$ & $\begin{array}{lr}\text { Assistência } & \text { de } \\
\text { enfermagem } & \text { a } \\
\text { mulheres } & \text { com } \\
\text { ansiedade } & \text { e } \\
\text { depressão } & \text { na } \\
\text { gravidez. } & \end{array}$ & $\begin{array}{l}\text { Demonstrar } \\
\text { importância do } \\
\text { conhecimento sobre } \\
\text { ansiedade e depressão } \\
\text { durante a gestação } \\
\text { para a melhoria da } \\
\text { qualidade na } \\
\text { assistência ao pré-natal } \\
\text { no âmbito da Atenção } \\
\text { Básica em Saúde. }\end{array}$ & $\begin{array}{l}\text { Verificou-se que ansiedade esta muito presente, } \\
\text { principalmente em mães adolescentes, mães com } \\
\text { baixa escolaridade, sem apoio familiar e solteiras, } \\
\text { evidenciando assim a influência de fatores } \\
\text { socioeconômicos como fatores de risco para } \\
\text { ansiedade na gestação. Outras situações como } \\
\text { gravidez não planejada, se revelou também um } \\
\text { agravo para muitas gestantes. }\end{array}$ \\
\hline 2 & Acta Paul Enferm. & $\begin{array}{l}\text { Silva et } \\
\text { al., } 2020 .\end{array}$ & $\begin{array}{l}\text { Estudo } \\
\text { clínico } \\
\text { randomizado, } \\
\text { simples-cego. }\end{array}$ & $\begin{array}{l}\text { Efeitos da } \\
\text { auriculoterapia na } \\
\text { ansiedade de } \\
\text { gestantes no pré- } \\
\text { natal de baixo } \\
\text { risco. }\end{array}$ & $\begin{array}{l}\text { Avaliar os efeitos da } \\
\text { auriculoterapia nos } \\
\text { níveis de ansiedade em } \\
\text { gestantes atendidas em } \\
\text { pré-natal de baixo } \\
\text { risco. }\end{array}$ & $\begin{array}{l}\text { A intervenção do profissional de saúde } \\
\text { acupunturista em atendimentos de gestante na } \\
\text { consulta pré-natal de baixo risco revelou-se } \\
\text { significativo na comparação entre os grupos } \\
\text { controle e intervenção com relação à diminuição da } \\
\text { ansiedade, evidenciando essa prática da Medicina } \\
\text { Tradicional Chinesa como prática favorável a ser } \\
\text { aplicada no período gestacional na terapêutica do } \\
\text { estado de ansiedade. }\end{array}$ \\
\hline 3 & $\begin{array}{l}\text { Rev enferm UFPE } \\
\text { On-line. }\end{array}$ & $\begin{array}{l}\text { Silva, } \\
\text { Leite, } \\
\text { Nogueira } \\
\quad \text { \& } \\
\text { Clapis, } \\
2015 .\end{array}$ & $\begin{array}{l}\text { Estudo } \\
\text { quantita-tivo, } \\
\text { epidemioló- } \\
\text { gico, } \\
\text { descritivo, de } \\
\text { corte } \\
\text { transversal e } \\
\text { correlacional. }\end{array}$ & $\begin{array}{l}\text { Ansiedade } \\
\text { depressão } \\
\text { gravidez: } \\
\text { caracterização de } \\
\text { gestantes que } \\
\text { realizaram pré- } \\
\text { natal em unidade } \\
\text { públicas de saúde. }\end{array}$ & $\begin{array}{l}\text { Avaliar a presença de } \\
\text { ansiedade e depressão } \\
\text { na gravidez } \\
\text { caracterizar o perfil } \\
\text { das gestantes. }\end{array}$ & $\begin{array}{l}\text { Observou-se que as gestantes apresentaram alguns } \\
\text { fatores de risco para a ocorrência desses transtornos } \\
\text { na gravidez já evidenciados na literatura como } \\
\text { baixa/média escolaridade, baixa renda familiar } \\
\text { mensal, histórico de complicações em gestações } \\
\text { anteriores e gravidez não planejada. Desta forma, } \\
\text { inferiu-se a necessidade de implementação de } \\
\text { intervenções para prevenir, detectar e tratar } \\
\text { transtornos psíquicos que podem permear a } \\
\text { gestação como a ansiedade e a depressão, como a } \\
\text { realização de triagem e monitoramento da saúde } \\
\text { mental durante todo o pré-natal. }\end{array}$ \\
\hline 4 & $\begin{array}{l}\text { Rev Esc Enferm } \\
\text { USP. }\end{array}$ & $\begin{array}{l}\text { Silva, } \\
\text { Nogueira } \\
\text {, Clapis, } \\
\text { \& Leite, } \\
2017 .\end{array}$ & $\begin{array}{l}\text { Estudo } \\
\text { descritivo e } \\
\text { correlacional, } \\
\text { de corte } \\
\text { transversal. }\end{array}$ & $\begin{array}{l}\text { Ansiedade na } \\
\text { gravidez: } \\
\text { prevalência } \\
\text { fatore associados. }\end{array}$ & $\begin{array}{l}\text { Avaliar a ocorrência } \\
\text { da ansiedade em } \\
\text { gestantes e os fatores } \\
\text { associados à sua } \\
\text { ocorrência; comparar a } \\
\text { presença de ansiedade } \\
\text { em cada trimestre } \\
\text { gestacional. }\end{array}$ & $\begin{array}{l}\text { A ansiedade esteve presente no estudo em } 26,8 \% \\
\text { das gestantes, sendo mais frequente no terceiro } \\
\text { trimestre }(42,9 \%) \text {. Ocupação }(\mathrm{p}=0,04) \text {, } \\
\text { complicações em gestações anteriores }(\mathrm{p}=0,00) \text {, } \\
\text { histórico de abortamento/ameaça de parto } \\
\text { prematuro }(\mathrm{p}=0,05) \text {, desejo materno em relação à } \\
\text { gravidez ( } \mathrm{p}=0,01) \text {, número de abortamentos } \\
(\mathrm{p}=0,02) \text { quantidade de cigarros consumidos } \\
\text { diariamente ( } \mathrm{p}=0,00) \text { e uso de drogas ( } \mathrm{p}=0,01) \\
\text { apresentaram associação estatisticamente } \\
\text { significativa com aocorência da ansiedade na } \\
\text { gravidez. A ansiedade se mostrou frequente na } \\
\text { gestação. }\end{array}$ \\
\hline 5 & $\begin{array}{l}\text { Rev. Bras. Saúde } \\
\text { Matern. Infant. }\end{array}$ & $\begin{array}{l}\text { Araújo, } \\
\text { Pacheco, } \\
\text { Pimenta, } \\
\text { \& Kac, } \\
2008 .\end{array}$ & $\begin{array}{l}\text { Estudo } \\
\text { prospecti-vo } \\
\text { transversal. }\end{array}$ & $\begin{array}{l}\text { Prevalência e } \\
\text { fatores associados } \\
\text { a sintomas de } \\
\text { ansiedade em uma } \\
\text { coorte de } \\
\text { gestantes } \\
\text { atendidas em um } \\
\text { centro de saúde do } \\
\text { município do Rio } \\
\text { de Janeiro. }\end{array}$ & $\begin{array}{lr}\text { Determinar } & \text { a } \\
\text { prevalência e } \quad \text { a } \\
\text { associação } & \text { entre } \\
\text { variáveis } & \text { sócio- } \\
\text { demográficas, } \\
\text { obstétricas, } \\
\text { nutricionais e sintomas } \\
\text { de ansiedade em } \\
\text { gestantes. }\end{array}$ & $\begin{array}{l}\text { Evidenciou-se no estudo que a prevalência de } \\
\text { ansiedade foi elevada nesta amostra de gestantes } \\
\text { acompanhadas em uma unidade básica de saúde. O } \\
\text { conhecimento dos fatores associados à ansiedade é } \\
\text { de fundamental importância para que a equipe } \\
\text { multidisciplinar possa intervir de forma precoce e } \\
\text { adequada no tratamento das gestantes. }\end{array}$ \\
\hline
\end{tabular}




\begin{tabular}{|c|c|c|c|c|c|c|}
\hline 6 & $\begin{array}{l}\text { Revista do } \\
\text { Programa de } \\
\text { Residência } \\
\text { Multiprofissional } \\
\text { em Atenção } \\
\text { Básica/Saúde da } \\
\text { Família. }\end{array}$ & $\begin{array}{l}\text { Boarolli } \\
\text { et al., } \\
2016 .\end{array}$ & $\begin{array}{l}\text { Estudo de } \\
\text { temporalidade } \\
\text { transversal e } \\
\text { natureza } \\
\text { quantita-tiva. }\end{array}$ & $\begin{array}{l}\text { Avaliação } \\
\text { estresse, de } \\
\text { depressão e } \\
\text { ansiedade em um } \\
\text { grupo de gestantes } \\
\text { cadastradas na } \\
\text { estratégia saúde } \\
\text { da família do } \\
\text { bairro } \\
\text { Sebastião, São } \\
\text { Criciúma. }\end{array}$ & $\begin{array}{l}\text { Identificar sintomas de } \\
\text { depressão, ansiedade e } \\
\text { sintomas de stress em } \\
\text { gestantes do bairro } \\
\text { São Sebastião na } \\
\text { cidade de Criciúma. }\end{array}$ & $\begin{array}{l}\text { A mulher quando gestante está vulnerável e exposta } \\
\text { a diversas exigências vivenciando uma fase de } \\
\text { reorganização corporal, bioquímica, hormonal, } \\
\text { familiar e social, fazendo-a ficar propensa a uma } \\
\text { multiplicidade de sentimentos. Sugere-se também, } \\
\text { analisar a situação familiar e financeira das } \\
\text { gestantes para se ter mais clareza do que gera tais } \\
\text { sintomas - ansiedade, depressão, estresse. Isto é, } \\
\text { com mais informações podemos intervir e auxiliar } \\
\text { estas pacientes que utilizam o (SUS), promovendo } \\
\text { uma melhor qualidade de vida, não apenas no } \\
\text { momento da gestação, mas para sua vida nos } \\
\text { demais sentidos e momentos. }\end{array}$ \\
\hline 7 & J Nurs Health. & $\begin{array}{c}\text { Alves, } \\
\text { Siqueira, } \\
\& \\
\text { Pereira, } \\
2018 .\end{array}$ & $\begin{array}{l}\text { Pesquisa } \\
\text { descritiva e } \\
\text { exploratória } \\
\text { com } \\
\text { abordagem } \\
\text { quan-titativa. }\end{array}$ & $\begin{array}{lr}\text { Inventário } & \text { de } \\
\text { ansiedade } & \text { Traço- } \\
\text { Estado } & \text { de } \\
\text { gestantes. } & \end{array}$ & $\begin{array}{l}\text { Identificar o nível de } \\
\text { ansiedade e o perfil } \\
\text { das gestantes usuárias } \\
\text { do Sistema Único de } \\
\text { Saúde de Pontal do } \\
\text { Araguaia, Mato } \\
\text { Grosso. }\end{array}$ & $\begin{array}{l}\text { Verificou-se no estudo que Houve predominância } \\
\text { de gestantes jovens, pardas, casadas, com ensino } \\
\text { médio, do lar, economicamente ativas, de baixa } \\
\text { renda. Embora as gestantes economicamente } \\
\text { inativas terem apresentado Ansiedade - Traço } \\
\text { Elevada, enquanto as economicamente ativas, } \\
\text { Ansiedade-Traço Moderada, não houve correlação } \\
\text { positiva, entre a situação da gestante no mercado de } \\
\text { trabalho e o escore de Ansiedade - Traço. }\end{array}$ \\
\hline 8 & $\begin{array}{l}\text { PSIC - Revista de } \\
\text { Psicologia da } \\
\text { Vetor Editora }\end{array}$ & $\begin{array}{l}\text { Baptista, } \\
\text { Baptista, } \\
\& \text { Torres, } \\
2006 .\end{array}$ & $\begin{array}{l}\text { Estudo } \\
\text { quanti- } \\
\text { qualitativo. }\end{array}$ & $\begin{array}{lr}\text { Associação } & \text { entre } \\
\text { suporte } & \text { social, } \\
\text { ansiedade } & \mathrm{e} \\
\text { depressão } & \text { em } \\
\text { estantes. } & \end{array}$ & $\begin{array}{l}\text { Avaliar a associação } \\
\text { entre o suporte social } \\
\text { com sintomatologia de } \\
\text { depressão e ansiedade } \\
\text { em gestantes, além de } \\
\text { verificar a prevalência } \\
\text { destes sintomas nesta } \\
\text { amostra. }\end{array}$ & $\begin{array}{l}\text { O papel do suporte social nas diversas fases da } \\
\text { vida é fundamental para o amortecimento de } \\
\text { fatores estressantes que ocorrem no cotidiano, } \\
\text { principalmente em momentos em que se } \\
\text { observam diversas modificações psicossociais e } \\
\text { fisiológicas como é o caso da gravidez e do } \\
\text { puerpério, sendo que o suporte social está } \\
\text { associado com a saúde mental, especificamente } \\
\text { com sintomatologia depressiva e ansiosa nos } \\
\text { estados gravídicos epuerperais. }\end{array}$ \\
\hline 9 & Rev Neurocienc & $\begin{array}{l}\text { Paz et al., } \\
2020 .\end{array}$ & $\begin{array}{l}\text { Estudo } \\
\text { qualitativo } \\
\text { descritivo. }\end{array}$ & $\begin{array}{l}\text { Ansiedade na } \\
\text { gestação de alto } \\
\text { risco: um reflexo } \\
\text { da atenção básica } \\
\text { no alto sertão da } \\
\text { Paraíba. }\end{array}$ & $\begin{array}{l}\text { Avaliar o grau de } \\
\text { ansiedade e } \\
\text { as características } \\
\text { ansiosas de gestantes de } \\
\text { alto risco na atenção } \\
\text { básica de cidades do } \\
\text { interior da Paraíba, } \\
\text { associado ao contexto } \\
\text { sociodemográfico. }\end{array}$ & $\begin{array}{l}\text { A ansiedade é desencadeada por estímulos } \\
\text { sensoriais que afeta a fisiologia do sistema } \\
\text { nervoso e propicia um estado psíquico que pode } \\
\text { afetar diretamente uma mulher e seu filho durante } \\
\text { a gestação, e isso pode ser ainda mais danoso se a } \\
\text { gestante for de alto risco. Nota-se que durante o } \\
\text { período gestacional é comum que as mães } \\
\text { desenvolvam quadro ansioso, com medo do pior } \\
\text { acontecer e instabilidade emocional, e isso } \\
\text { somado às características sociais e clínicas da } \\
\text { gestante pode agravar a predisposição a esses } \\
\text { sintomas ansiosos. }\end{array}$ \\
\hline 10 & $\begin{array}{l}\text { Rev. Ciênc. Saúde } \\
\text { Nova Esperança. }\end{array}$ & $\begin{array}{l}\text { Severo, } \\
\text { Santos, \& } \\
\text { Pereira, } \\
2017 .\end{array}$ & $\begin{array}{c}\text { Pesquisa } \\
\text { exploratória } \\
\text { descritivo de } \\
\text { natureza } \\
\text { quantitativa. }\end{array}$ & $\begin{array}{ll}\text { Ansiedade } & \text { em } \\
\text { mulheres } & \text { no } \\
\text { período } & \\
\text { gestacional. } & \end{array}$ & $\begin{array}{l}\text { Investigar níveis de } \\
\text { ansiedade em mulheres } \\
\text { no período gestacional. }\end{array}$ & $\begin{array}{l}\text { A gestação é compreendida como um momento } \\
\text { formidável na vida da mulher, ainda que algumas } \\
\text { delas vivenciem nesse período problemas que } \\
\text { resultem em agravos a saúde mental, a exemplo } \\
\text { da alta prevalência de ansiedade entre gestantes } \\
\text { identificada nesta investigação. Assim, remete à } \\
\text { necessidade de discussão e reflexão no que se } \\
\text { refere à assistência a mulher no período gravídico, } \\
\text { pois na atualidade, na grande maioria das vezes, } \\
\text { esta assistência se limita as necessidades } \\
\text { orgânicas e os aspectos referentes à saúde mental } \\
\text { não são identificados ou trabalhados nesta } \\
\text { oportunidade, fato este que vem acarretando uma } \\
\text { alta prevalência de doenças mentais no período } \\
\text { gravídico puerperal. }\end{array}$ \\
\hline 11 & $\begin{array}{c}\text { Práticas } \\
\text { Integrativas e } \\
\text { Complementares: } \\
\text { Visão Holística e } \\
\text { Multidisci-plinar. }\end{array}$ & $\begin{array}{l}\text { Costa } e t \\
\text { al., } 2007 .\end{array}$ & $\begin{array}{l}\text { Estudo } \\
\text { qualitativo. }\end{array}$ & $\begin{array}{lr}\text { Acupuntura } & \text { no } \\
\text { tratamento } & \text { de } \\
\text { ansiedade } & \text { em } \\
\text { gestantes r na } \\
\text { atenção primária a } \\
\text { saúde. }\end{array}$ & $\begin{array}{lr}\text { Analisar sobre o efeito } \\
\text { da acupuntura no } \\
\text { tratamento } & \text { de } \\
\text { ansiedade } & \text { em } \\
\text { gestantes na atenção } \\
\text { primaria a saúde. }\end{array}$ & $\begin{array}{l}\text { Acupuntura tem grande potencial terapêutico no } \\
\text { tratamento, levando a redução significativa da } \\
\text { patologia. Estudos mostram que a estimulação dos } \\
\text { pontos de acupuntura específicos para tratamento } \\
\text { de depressão e ansiedade liberam noradrenalina no } \\
\text { Sistema Nervoso Central, em que os pacientes com } \\
\text { ansiedade têm altas concentrações. Neste contexto, } \\
\text { as Práticas Integrativas Complementares vem sendo } \\
\text { cada vez mais utilizados, auxiliando na diminuição } \\
\text { do uso de fármaco terapias, bem como na redução } \\
\text { dos níveis de ansiedade e alivio da dor durante a } \\
\text { gestação. }\end{array}$ \\
\hline
\end{tabular}




\begin{tabular}{|c|c|c|c|c|c|c|}
\hline 12 & Revista Nursing, & $\begin{array}{c}\text { Silva et } \\
\text { al., } 2020 .\end{array}$ & $\begin{array}{c}\text { Estudo } \\
\text { descritivo } \\
\text { exploratório } \\
\text { de abordagem } \\
\text { quantitativa. }\end{array}$ & $\begin{array}{lr}\text { Risco } & \text { de } \\
\text { depressão } & \text { e } \\
\text { ansiedade } & \text { em } \\
\text { gestantes } & \text { na } \\
\text { atenção primária. }\end{array}$ & $\begin{array}{l}\text { Identificar os riscos } \\
\text { para depressão e } \\
\text { ansiedade } \quad \text { em } \\
\text { gestantes de uma } \\
\text { unidade de saúde da } \\
\text { Atenção Primária. }\end{array}$ & $\begin{array}{l}\text { Evidenciou-se elevados índices de risco de } \\
\text { ansiedade e risco moderado de depressão entre as } \\
\text { gestantes analisadas, com elevada significância } \\
\text { estatística. É necessário que os profissionais de } \\
\text { saúde da Atenção Primária tenham uma visão mais } \\
\text { ampliada acerca de transtornos de saúde mental, } \\
\text { identificando precocemente possíveis alterações e } \\
\text { abordando por meio da equipe multidisciplinar, } \\
\text { possíveis estratégias de enfrentamento individual. }\end{array}$ \\
\hline 13 & $\begin{array}{l}\text { R. Pesq Cuid. } \\
\text { Fundam. Online. }\end{array}$ & $\begin{array}{l}\text { Martins } \\
\text { et al., } \\
2020 .\end{array}$ & $\begin{array}{l}\text { Estudo } \\
\text { transversal. }\end{array}$ & $\begin{array}{lr}\text { Efeito } & \text { da } \\
\text { acupuntura } & \text { para } \\
\text { alívio } & \text { dos } \\
\text { desconfortos } & \\
\text { físicos } & \text { e } \\
\text { emocionais } & \text { na } \\
\text { gestação. }\end{array}$ & $\begin{array}{l}\text { Analisar os efeitos da } \\
\text { acupuntura nos } \\
\text { desconfortos físicos e } \\
\text { emocionais presentes } \\
\text { na gestação. }\end{array}$ & $\begin{array}{l}\text { A acupuntura contribuiu positivamente na melhoria } \\
\text { de diversos sintomas físicos e emocionais, como: } \\
\text { relaxamento do corpo, estresse, sono, cefaleia, } \\
\text { ansiedade, humor, ânimo, dentre outros, podendo } \\
\text { ser usada como alternativa para a promoção da } \\
\text { saúde gestacional. }\end{array}$ \\
\hline
\end{tabular}

Fonte: Autores (2021).

No Quadro 1, tem-se a apresentação dos artigos selecionados para o estudo conforme número do artigo, periódico, autor e ano de publicação, tipo de estudo, título, objetivo, resultados em evidências e conclusões importantes, com a finalidade de facilitar o desenvolvimento da discussão. A partir do estudo dos artigos estabeleceram-se discussões relevantes para observações das produções científicas relacionadas à pesquisa.

No gráfico a seguir, estão expostos os periódicos e a quantidade de artigos encontrados na seleção da amostra final dos artigos que serão trabalhados na elaboração do referido estudo.

Gráfico 1. Distribuição dos artigos conforme periódico e quantidade.

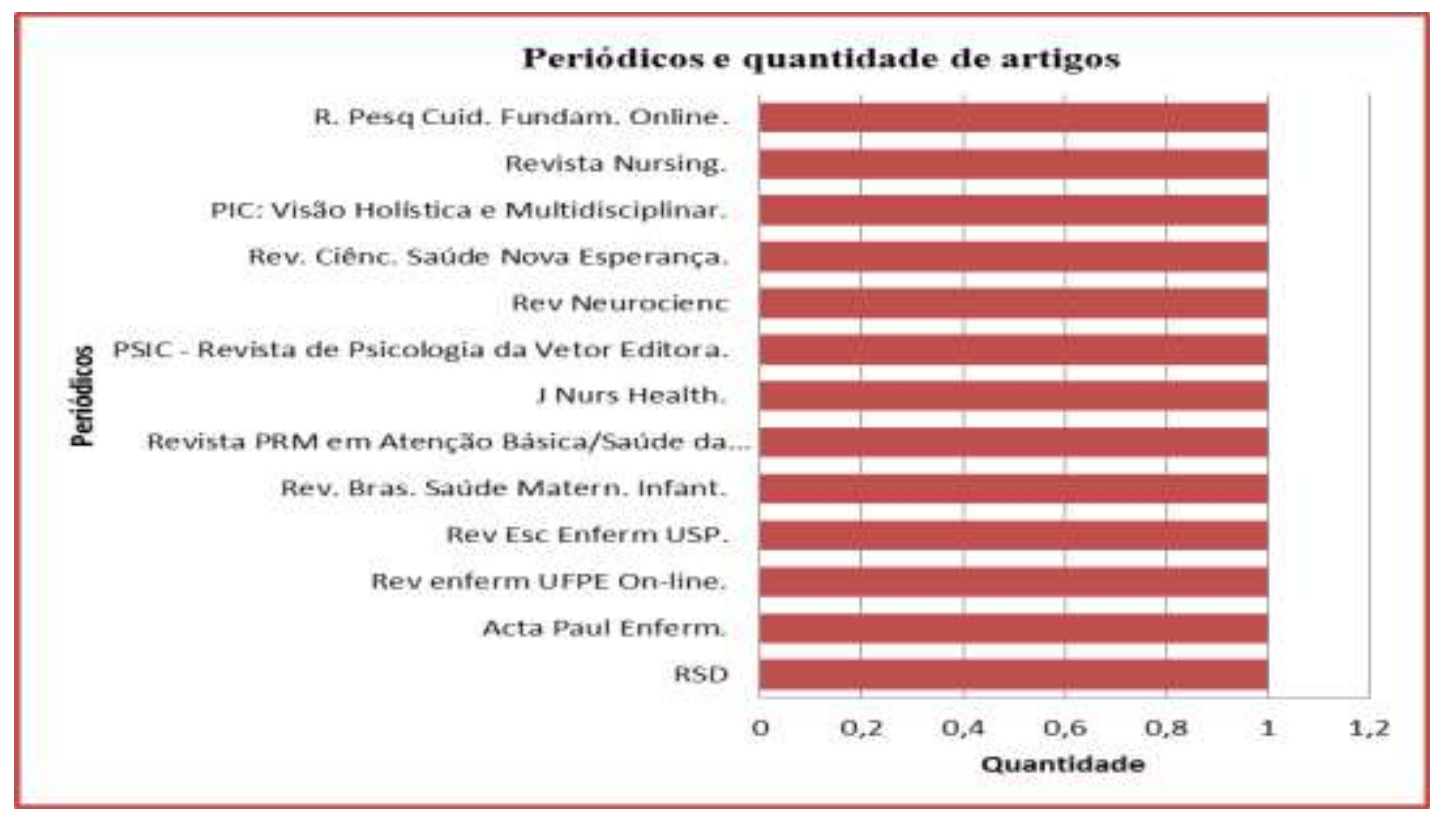

Fonte: Autores (2021).

Segundo o gráfico ilustrado acima, pode-se observar os periódicos e a quantidade de artigos que foram publicados de acordo com a amostra final do referido estudo. Dessa forma, verifica-se que na Research, Society and Development ocorreu (1) publicação, Acta Paul Enferm (1), Rev Enferm UFPE Online (1), Rev Esc Enferm USP (1), Rev Bras Saúde Materno Infant (1), Revista PRM em Atenção Básica/Saúde da Família (1), J Nurs Health (1), PSIC - Revista de Psicologia da Vetor Editora (1), Rev Neurocien (1), Rev. Ciên. Saúde. Nova Esperança (1), PIC: Visão Holística e Multidisciplinar (1), Revista Nursing (1), R Pesq Cuid Fundam Online (1). Assim, totalizando 13 artigos para serem trabalhados na elaboração do presente estudo. 
Gráfico 2. Distribuição dos artigos conforme os tipos de estudo e quantidade.

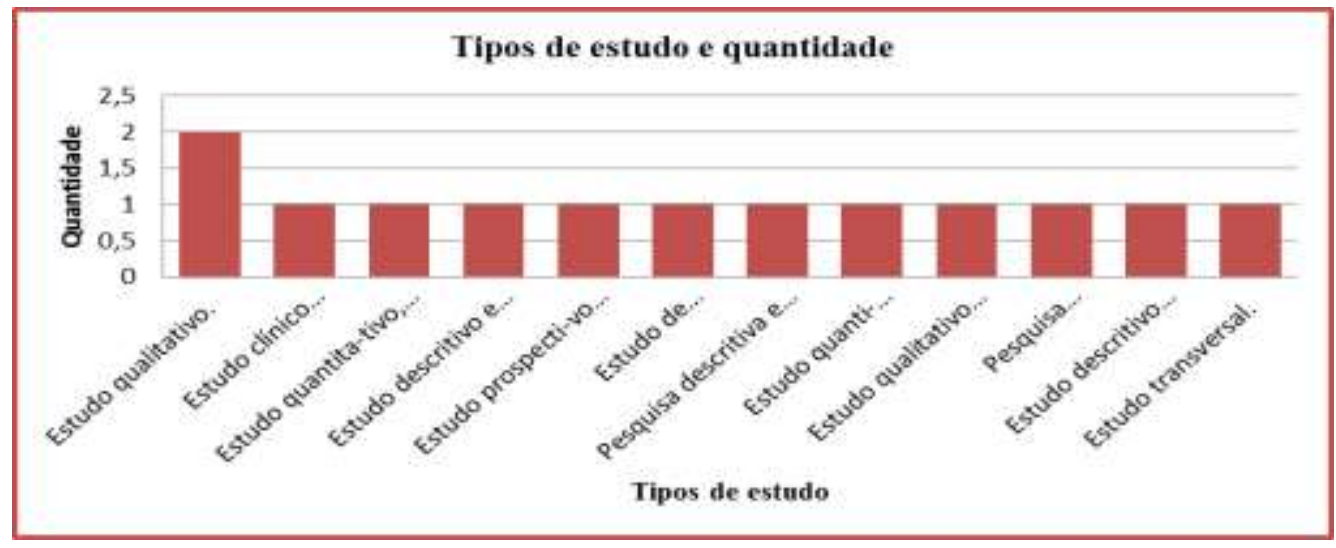

Fonte: Autores (2021).

Ao analisar o gráfico representado acima, identificam-se os tipos de estudo e a quantidade de artigos publicados. Nota-se que evidenciou-se um total de: Estudo qualitativo (2), estudo clínico randomizado, simples-cego (1), estudo quantitativo epidemiológico, descritivo de coorte transversal e correlacional (1), estudo descritivo e correlacional, de coorte correlacional transversal (1), estudo prospectivo transversal (1), estudo de temporalidade transversal e natureza quantitativa (1), Pesquisa descritiva e exploratória com abordagem quantitativa (1) estudo quanti-qualitativo (1), estudo qualitativo descritivo (1), Pesquisa exploratória descritiva de natureza quantitativa (1), estudo descritivo de abordagem quantitativa (1) estudo transversal (1).

Gráfico 3. Distribuição dos artigos conforme ano de publicação e quantidade.

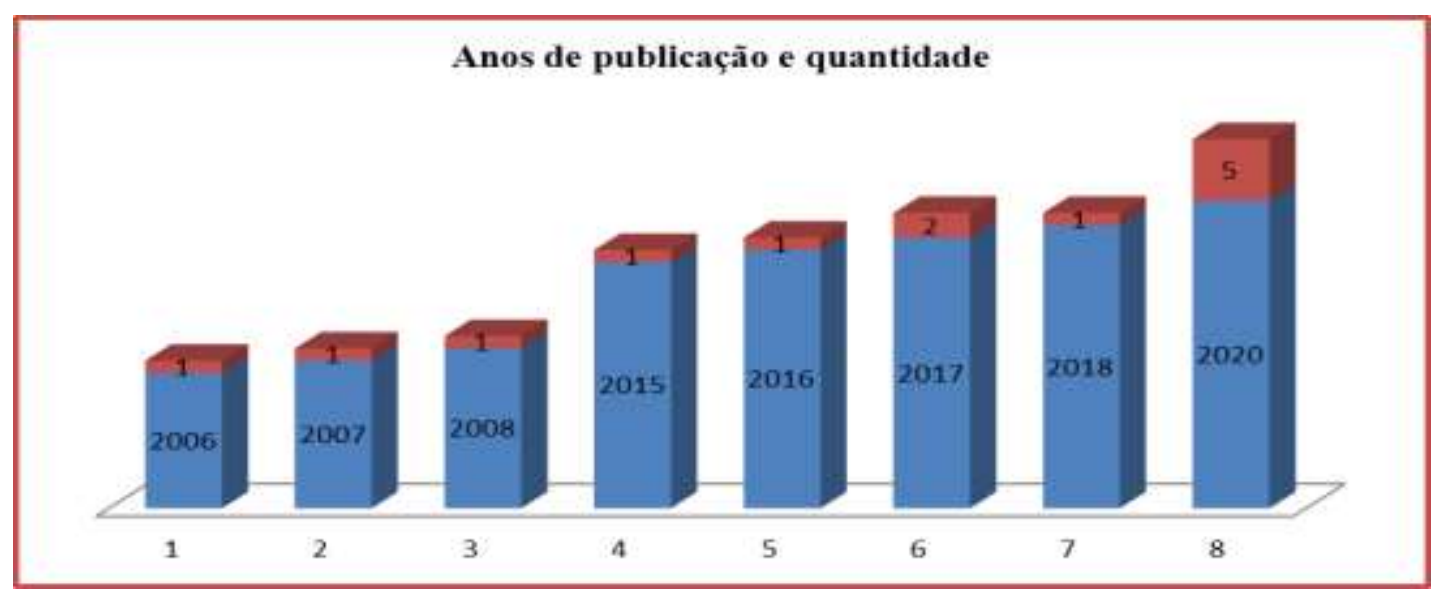

Fonte: Autores (2021).

Diante do gráfico representado acima, percebe-se os anos de publicação e a quantidade de artigos publicados na amostra final do referido estudo. Verifica-se que no ano de 2006 ocorreu (1) publicação, 2007 (1), 2008 (1), 2015 (1), 2016 (1), 2017 (2), 2018 (1) e 2020 (5) publicações, chegando-se um total de 13 artigos para serem discutidos na construção do presente estudo. 
Gráfico 4. Distribuição dos artigos conforme ano de publicação e porcentagem.

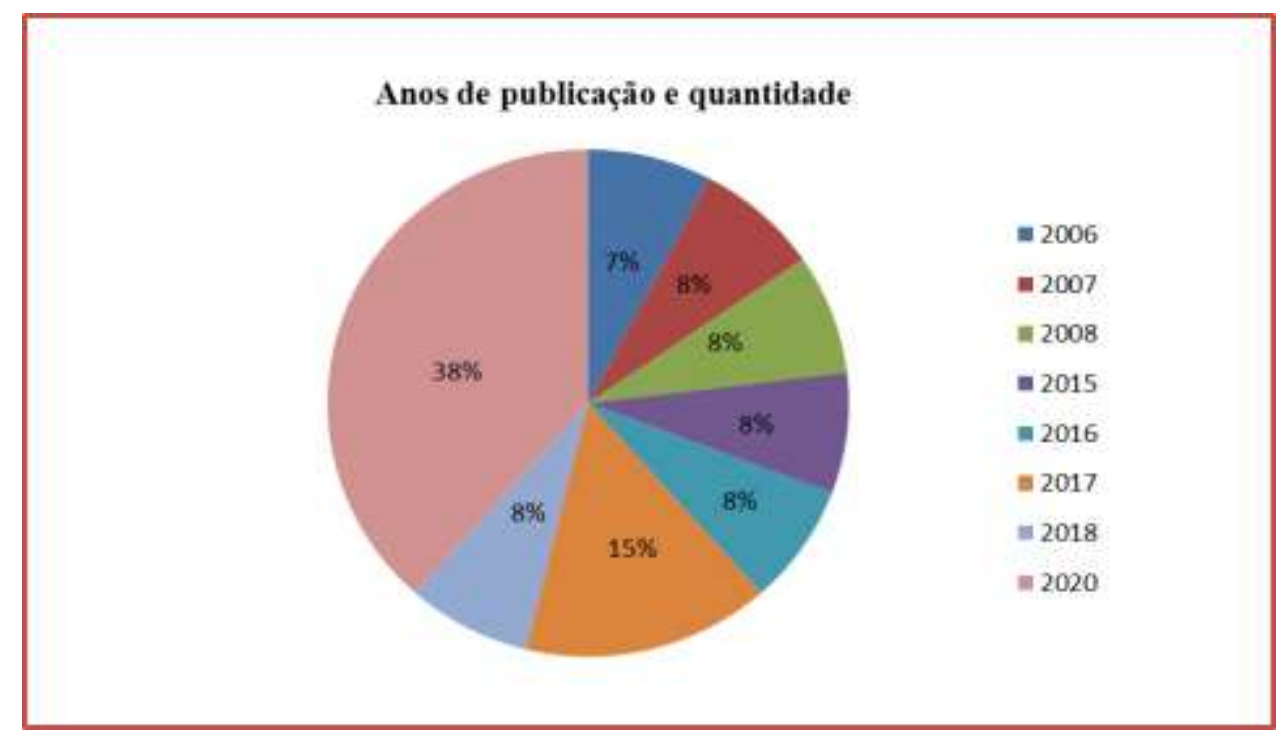

Fonte: Autores (2021).

De acordo com o gráfico ilustrado acima, identifica-se os anos de publicação e a porcentagem de artigos encontrados. Constata-se que no ano de 2006 houve (7\%) das publicações, 2007 (8\%), 2008 (8\%), 2015 (8\%), 2016 (8\%), 2017 (15\%), 2018 (8\%), e 2020 (38\%) das publicações encontras na amostra final do referido estudo. Dessa forma, nota-se que o ano de 2020 houve o maior número de publicações, sendo que, foram adotados os aspectos metodológicos dos critérios de inclusão e exclusão na elaboração do presente estudo.

Segundo Costa et al. (2007), o período gestacional ocorre uma série de transição na vida da mulher, tanto no campo da sexualidade como no campo psicossocial, o que gera ansiedade com somatizações difusas (insônia, dores musculares inespecíficas, taquicardia, enxaquecas, sudorese, aumento da frequência urinária, agitação ou depressão psíquica, ondas de calor, irregularidade no ciclo menstrual, queda no desejo sexual.

A gestação envolve mudanças nos aspectos hormonais, físicos, psicológicos, familiares e sociais, na possibilidade de adequações e reestruturações na vida das mulheres. Essas mudanças têm desencadeado, muitas vezes, um processo de vulnerabilidade às mulheres grávidas podendo agravar à saúde mental e desenvolver transtornos mentais. Os distúrbios mentais podem causar sofrimento psíquico, comprometimento funcional e interferência na qualidade de vida da gestante, com aumento de sintomatologias influencia diretamente no desempenho das suas atividades cotidianas (Araújo et al., 2020).

Assim, a Política Nacional de Saúde Mental obtém estratégias e diretrizes adotadas pelo país no objetivo de organizar a assistência a pacientes e seus familiares voltado para atenção necessária aos distúrbios. Tendo em vista que os distúrbios de ansiedade implicam em grandes repercussões negativas para a saúde da mulher durante o período gestacional, uma vez que seus sintomas interferem no autocuidado e na adesão ao tratamento (Araújo et al., 2020).

A prevalência da ansiedade, aflige cerca de $20 \%$ das mulheres. Dessa forma, os riscos obstétricos que envolvem o desenvolvimento de uma gestação colocam a mulher em estado susceptível à ansiedade, deixando-a dual: frágil, por medo das alterações gravídicas, e ao mesmo tempo feliz pelo processo de concepção e formação de uma nova vida. A ansiedade causa mudanças endócrinas e também comportamentais, como busca pelo tabaco, alimentação inadequada e não comprometimento com as consultas de pré-natal, e quanto maior o nível de ansiedade durante a gestação, maior será a probabilidade do surgimento de depressão puerperal e de efeitos deletérios, tanto para a gestante quanto para o recém-nascido (Silva et al., 2020). 
As práticas integrativas estão em constante avanço no meio das intervenções em saúde, caracterizando-as em escolha de preferência para tratar transtornos de ansiedade, uma vez que possuem riscos diminuídos de efeitos adversos, bem como têm apresentado resultados positivos, demonstrando significativa redução da ansiedade e aumento no vínculo materno-fetal. De acordo com o Ministério da Saúde, essas práticas devem ser implementadas para reduzir a ansiedade em gestantes, de modo que não ocorram transtornos mais graves no pós-parto, sendo a auriculoterapia uma das Práticas Integrativas e Complementares em saúde que pode favorecer a redução da ansiedade (Silva et al., 2020).

Em virtude de suas consequências, a ansiedade é considerada um dos principais fatores de risco para o desenvolvimento da gravidez, uma vez que o seu desenvolvimento durante a gestação pode comprometer o feto, estando associado a resultados neonatais negativos como a prematuridade, baixo peso ao nascer, escores inferiores de Apgar, déficit no desenvolvimento fetal, além de efeitos duradouros sobre o desenvolvimento físico e psicológico do filho e às complicações obstétricas como sangramento vaginal e ameaça de abortamento, além de ser um dos principais fatores de risco para a depressão pós-parto (Silva, Leite, Nogueira, \& Clapis, 2015).

Nesse sentido, verifica-se a necessidade de implementações de intervenções para prevenir, detectar e tratar transtornos psíquicos que podem permear a gestação como a ansiedade, como a realização de triagem e monitoramento da saúde mental durante todo o pré-natal. Para tanto, requer-se a capacitação dos profissionais envolvidos na assistência pré-natal, a enfermagem é inserida na atenção primária à saúde que devem incorporar a saúde mental da mulher nas práticas assistenciais do cotidiano, assim como o apoio dos gestores de saúde por meio de políticas e programas que envolvam a saúde mental das mulheres, em especial durante a gestação (Silva, Leite, Nogueira, \& Clapis, 2015).

A gravidez é influenciada por diversos fatores, desde os de natureza biológica até as características sociais e econômicas da população, além do acesso e qualidade técnica dos serviços de saúde disponíveis à população, que garantem uma gestação segura. Constata-se que a gestação e o puerpério são caracterizados por períodos que requerem atenção e cuidados essenciais qualificados, que tenham como base a prevenção de complicações, conforto físico e emocional e ações educativas que possam ofertar à mulher apetrechos para cuidar de si e do filho. O profissional que auxiliar estas futuras mamães deve ser sensível e valorizar a linguagem corporal e oral das mesmas, pois elas são influenciadas por expectativas sociais referentes ao desempenho da maternidade (Boarolli et al., 2016).

Segundo Baptista, Baptista, e Torres (2006), o suporte social, bem como o suporte familiar é muito importante para a manutenção da saúde mental e enfrentamento de situações estressantes, além da adequação de comportamentos maternos em relação aos filhos. O suporte social também vem sendo associado à diversas outras medidas, tais como competência pessoal, comportamentos de adesão a tratamentos de saúde, estratégias de enfrentamento, percepção de controle, senso de estabilidade e bem estar psicológico, dentre outros.

A ansiedade é um estado emocional de ampla complexidade, que engloba a antecipação de riscos com um certo grau de incerteza em relação à sua ocorrência. Tendo isso em mente, a fisiopatologia da ansiedade envolve a soma de fatores como o sentimento de apreensão, tensão, nervosismo e/ou medo; unidos com as respostas fisiológicas de excitação cardiovascular, sensorial, endócrina e no sistema músculo-esquelético. Além dos efeitos motores e viscerais, a ansiedade afeta ainda o pensamento, a percepção e a aprendizagem, sendo uma resposta condicionada a um estímulo ambiental específico (Paz et al., 2020).

Assim, a gestação deve ser encarada como período de vulnerabilidade para manifestação de agravos a saúde mental, tornando-se essencial o envolvimento de todos os membros da família no processo gestacional e puerperal além da necessidade de uma assistência pré-natal mais efetiva que busque trabalhar além das necessidades orgânicas as demandas psíquicas. Pois quando surgem os problemas psíquicos no período gestacional e no pós-parto os prejuízos não se limitam apenas a mulher, estes afetam diretamente a criança. Sendo assim, reitera-se a importância de trabalhar propostas de prevenção e cuidados a 
saúde mental no período gestacional, visto que proporciona muitos benefícios a saúde do binômio mãe-filho, contribuindo para a formação de vínculos emocionais que favorecem uma maternidade participativa e afetiva (Severo, Santos, \& Pereira, 2017).

A ansiedade pode estar associada ao trabalho de parto prematuro, baixo peso ao nascer e problemas no desenvolvimento da criança. Nas gestantes, aumentam o risco de exporem-se ao tabaco, álcool e outras drogas, além do risco de desnutrição e a dificuldade de seguir orientações dadas no pré-natal de rotina, diminuindo inclusive a frequência nessas consultas, o que tem sido associado ao risco de mortalidade neonatal (Silva et al., 2020).

A preocupação em avaliar a saúde mental das gestantes, infelizmente tem despertado pouca atenção entre a sociedade, isto por que as próprias mulheres podem relutar em compartilhar sintomas de tristeza e irritabilidade, além de haver uma tendência a se concentrar na saúde física (materna e fetal) durante a gravidez, e não na saúde mental. Diante disso, é fundamental que haja um rastreio para identificar o risco de depressão e ansiedade nas gestantes e que esses sinais sejam precocemente detectados, com o objetivo de encaminhar aos profissionais especializados para diagnóstico e tratamento imediato, evitando assim, consequências futuras ao binômio mãe-filho (Silva et al., 2020).

A maternidade é uma experiência pessoal vivenciada por mulheres de modo singular, portanto, a atenção pré-natal deve incluir não somente práticas de promoção e prevenção da saúde, como também de diagnóstico e tratamento adequado de possíveis problemas decorrentes desse período. A gestação é um período de grandes mudanças para a mulher, representadas por uma variação hormonal e alterações nas características corporais que repercutem em seu cotidiano, as quais, apesar de serem necessárias para o desenvolvimento fetal, podem provocar certos desconfortos (Martins et al., 2020).

A terapêutica medicamentosa deve ser uma opção a ser utilizada com cautela, pois podem ocorrer implicações na saúde materna e infantil, devendo ser estimulado o uso de terapias não farmacológicas como métodos para aliviar esses desconfortos. Os tratamentos na gravidez são mais complexos, minuciosos e delicados, tendo em vista as limitadas opções terapêuticas, pelas implicações para a mãe e para o feto. Uma forma de terapia durante a gravidez é a acupuntura, que pode ser eficaz na redução de sintomas, principalmente, de dor e, consequentemente, melhorar a qualidade de vida das gestantes, em comparação com os cuidados habituais (Martins et al., 2020).

Uma vez conhecendo e comprovando seus benefícios, outros profissionais de saúde, principalmente, enfermeiros, poderão realizá-la, se aptos, compreender ou ainda indicar o uso da acupuntura como um tratamento não farmacológico para alívio de desconfortos, com o intuito de possibilitar cuidados de enfermagem qualificados que tenham como base a promoção da saúde, a prevenção de complicações, o bem-estar físico e emocional das gestantes (Martins et al., 2020).

\section{Conclusão}

Evidenciou-se no estudo, que é necessário que os enfermeiros realizem um acolhimento integral durante o pré-natal, investigando questões clínicas e também psicossociais para que assim possam contribuir, de maneira significativa, na melhora nos níveis de ansiedade e depressão desta gestante, proporcionando um acompanhamento pré-natal de qualidade.

Nesse sentido, recomenda-se que os enfermeiros que realizam a assistência à mulher durante o período gestacional tenham conhecimento sobre a relação da ansiedade em gestantes e incluam a avaliação desses sinais e sintomas na rotina de cuidados. A identificação dos fatores de risco da ansiedade no pré-natal pode contribuir para o desenvolvimento de estratégias a fim de identificar grupo de risco de mulheres com necessidade de intervenção durante a assistência no pré-natal.

Diante desse contexto, destaca-se a importância em se identificar precocemente sinais e sintomas de ansiedade durante o pré-natal, bem como promover estratégias para melhoria da assistência durante esse período através de uma anamnese psicossocial, de forma a avaliar o estado emocional dessa gestante enfatizando questões específicas de saúde mental. Torna-se importante a realização de estudos futuros com a finalidade de ampliar a produção científica a respeito dessa temática tão relevante, sendo de suma importância, no sentido de aprofundar discussões que possam contribuir para a promoção da 
saúde e na melhoria da qualidade de vida dessas pacientes.

\section{Referências}

Alves, J. S., de Siqueira, H. C. H., \& Pereira, Q. L. C. (2018). Inventário de ansiedade Traço-Estado de gestantes. Journal of Nursing and Health, 8(3).

Araújo, A. B., Nunes, Á. C. M., Pessoa, A. V. S., Gomes, B. C., Rodrigues, E., de Macedo Sousa, L., ... \& de Freitas Soares, F. A. (2020). Assistência de enfermagem a mulheres com ansiedade e depressão na gravidez: uma revisão integrativa. Research, Society and Development, 9(10), e4349106961e4349106961.

Araújo, D. M. R., Pacheco, A. H. D. R. N., Pimenta, A. M., \& Kac, G. (2008). Prevalência e fatores associados a sintomas de ansiedade em uma coorte de gestantes atendidas em um centro de saúde do município do Rio de Janeiro. Revista Brasileira de Saúde Materno Infantil, 8(3), 333 -340.

Augusto, C. A., Souza, J. P. D., Dellagnelo, E. H. L., \& Cario, S. A. F. (2013). Pesquisa Qualitativa: rigor metodológico no tratamento da teoria dos custos de transação em artigos apresentados nos congressos da Sober (2007-2011). Revista de Economia e Sociologia Rural, 51 (4), $745-764$.

Baptista, M. N., Baptista, A. S. D., \& Torres, E. C. R. (2006). Associação entre suporte social, depressão e ansiedade em gestantes. Psic: revista da Vetor Editora, 7(1), 39-48.

Boarolli, M., Pacheco, T., Ceretta, L. B., Birollo, I. V. B., Amboni, G., \& Gomes, K. M. (2016). Avaliação de estresse, depressão e ansiedade em um grupo de gestantes cadastradas na estratégia saúde da família do bairro São Sebastião, Criciúma. Revista do Programa de Residência Multiprofissional em Atenção Básica/Saúde da Família, 3.

Botelho, L. L. R., de Almeida Cunha, C. C., \& Macedo, M. (2011). O método da revisão integrativa nos estudos organizacionais. Gestão e sociedade, 5(11), $121-136$.

Costa, N., Varela, S. M., Pereira, J. L. D., da Ponte, M. D., Pereira, A. M. M., da Silva Torres, R., \& de Brito, A. D. Acupuntura no tratamento de ansiedade em gestantes na atenção primária a saúde.

Paz, M. M. S., Diniz, R. D. M. C., de Oliveira Almeida, M., Cabral, N. O., Mendes, C. K. T. T., de Araújo, J. S. S., \& de Assis, T. J. C. F. (2020). Ansiedade na gestação de alto risco: um reflexo da atenção básica no alto sertão da Paraíba. Revista Neurociências, 28, 1-21.

Ercole, F. F., Melo, L. D., \& Alcoforado, C. L. G. C. (2014). Revisão integrativa versus revisão sistemática. Rev Min Enferm, 18(1), 9-12.

Ferenhof, H. A., \& Fernandes, R. F. (2016). Desmistificando a revisão de literatura como base para redação científica: método SSF. Revista ACB, 21(3), 550563.

Maria de Jesus Silva, M., Peres Rocha Carvalho Leite, E., Alves Nogueira, D., \& José Clapis, M. (2015). Ansiedade e depressão na gravidez: caracterização de gestantes que realizaram pré-natal em unidades públicas de saúde. Journal of Nursing UFPE/Revista de Enfermagem UFPE.

Martins, E. S., Rocha, L. M. A., de Jesus Araújo, A. P., Tavares, T. M. C. L., Castro, R. C. M. B., \& Pinheiro, A. K. B. (2020). Efeito da acupuntura para alívio dos desconfortos físicos e emocionais na gestação. Revista de Pesquisa: Cuidado é Fundamental, 226-231.

Mendes, K. D. S., Silveira, R. C. D. C. P., \& Galvão, C. M. (2008). Revisão integrativa: método de pesquisa para a incorporação de evidências na saúde e na enfermagem. Texto \& contexto enfermagem, 17(4), 758-764.

Pereira, A. S., Shitsuka, D. M., Parreira, F. J., \& Shitsuka, R. (2018). Metodologia da pesquisa científica.

Silva Pereira, V. C. L., dos Santos, A. F., \& Severo, M. E. V. (2017). Ansiedade em mulheres no período gestacional. Revista de Ciências da Saúde Nova Esperança, 15(1), 80-91.

Silva, G. F. P., dos Santos, S. V., do Nascimento, J. W. A., de Santana, F. S., de Medeiros, J. S., \& de Jesus, S. B. (2020). Risco de depressão e ansiedade em gestantes na atenção primária. Nursing (São Paulo), 23(271), 4961-4970.

Silva, H. L. D., Almeida, M. V. D. S., Diniz, J. D. S. P., Leite, F. M. C., Moura, M. A. V., Bringuente, M. E. D. O., \& Amorim, M. H. C. (2020). Efeitos da auriculoterapia na ansiedade de gestantes no pré-natal de baixo risco. Acta Paulista de Enfermagem, 33.

Silva, M. M. D. J., Nogueira, D. A., Clapis, M. J., \& Leite, E. P. R. C. (2017). Ansiedade na gravidez: prevalência e fatores associados. Revista da Escola de Enfermagem da USP, 51 .

Soares, C. B., Hoga, L. A. K., Peduzzi, M., Sangaleti, C., Yonekura, T., \& Silva, D. R. A. D. (2014). Revisão integrativa: conceitos e métodos utilizados na enfermagem. Revista da Escola de Enfermagem da USP, 48(2), 335-345.

Sousa, L. M. M., Marques-Vieira, C. M. A., Severino, S. S. P., \& Antunes, A. V. (2017). A metodologia de revisão integrativa da literatura em enfermagem. 21(2), 17 .

Souza, M. T. D., Silva, M. D. D., \& Carvalho, R. D. (2010). Revisão integrativa: o que é e como fazer. Einstein, 8(1), $102-106$. 